\title{
Thermal effect of the welding process on the dynamic behavior of the HSS constitutive materials of a fillet welded joint
}

\author{
J. Carrier ${ }^{1,2, a}$, E. Markiewicz ${ }^{1}$, G. Haugou ${ }^{1}$, D. Lebaillif $^{2}$, N. LeConte $^{1}$ \\ AND H. NACEUR ${ }^{1}$ \\ 1 Université de Valenciennes - LAMIH UMR CNRS 8201, Le Mont-Houy, CISIT, 59313 Valenciennes Cedex 9, France \\ 2 Nexter Systems, 11 Allée des Marronniers, 78022 Versailles, France
}

Received 1 February 2016, Accepted 5 September 2016

\begin{abstract}
Welded joints, due to their manufacturing process, are commonly weakened areas. This study provides a pragmatic methodology to analyze the dynamic behavior of the Base Metal (BM) and the HeatAffected Zone (HAZ) of an HSS (High Strength Steel) fillet welded joint. Firstly, a specific approach has been developed to generate the HAZ material using a thermal treatment. Hardness and grain size are used to validate the replicated HAZ. This approach appears efficient and repeatable. Secondly, the true stressstrain quasi-static and dynamic behaviors up to failure of the BM and the HAZ have been determined. This characterization was performed thanks to a video tracking procedure and Bridgman-LeRoy correction. The comparison between these two materials shows that the thermal field of the welding process increases the HAZ yield stress and hardening while decreasing the strain at failure. It appears that the base metal is not rate sensitive from quasi-static up to $1350 \mathrm{~s}^{-1}$. On the contrary, the heat affected material appears to be rate sensitive, but by softening. This unexpected dynamic material softening requires further analyses. A first Finite Element (FE) numerical analysis on a welded substructure submitted to impact loading shows a strong influence of the HAZ on the initiation of failure mechanisms.
\end{abstract}

Key words: HSS fillet welded assembly / replicated HAZ / materials dynamic behavior and failure

\section{Introduction}

Finite element modeling is currently used to model the dynamic behavior of structures submitted to impact or blast events. It allows us to design armoured vehicles by evaluating the strength and integrity of the structure against battlefield threats. Welded joints, due to their manufacturing process, are weakened areas. Since it is difficult to correctly model the failure of welded joints using macro-scale models in structural computations, a meso-scale model approach is first proposed in order to understand the physics. This approach requires to characterize the mechanical properties up to failure of the welded joint constitutive materials: Base Metal (BM), Heat-Affected Zone (HAZ) and Weld Metal (WM). In this paper, only the BM and the HAZ are presented. Multiscale approaches have already been successfully applied on a mild-steel spot-welded assembly $[1,2]$ or on an aluminum welded joint [3]. In the present study, the difficulty relies on the particular nature of the fillet weld assembly in terms of geometry (large thickness) and constitutive

\footnotetext{
${ }^{a}$ Corresponding author: J.CARRIER@nexter-group.fr
}

material (HSS armor material). Several studies about the mechanical strength of welded assemblies published in the open literature cover a large field of loads: fatigue [4], quasi-static [5] and low velocity loads [6]. However, finite element models of military applications dealing on rapid dynamic loadings are not well developed in the literature. Gaudreault [7] is one of the few to present a study dedicated to a welded HSS joint subjected to an explosion. The welded joint is modeled by a shell element with the HAZ material properties. The weld geometry is not considered so the stress concentration (and the fracture behavior) cannot be really predictive. Few papers report the material behavior at high strain rates of HSS used for armoured vehicles [8,9]. Even fewer report material behavior under tensile loads, or present the dynamic behavior of welded assemblies manufactured using these HSS. Besides, open literature does not cover the mechanical strength of the associated HAZ material. This paper focuses on a pragmatic methodology to replicate the HAZ material using a thermal treatment and on the comparison between these two materials. Quasi-static and dynamic behavior up to failure of the BM and the HAZ are characterized and analyzed. Then, as a first attempt to 


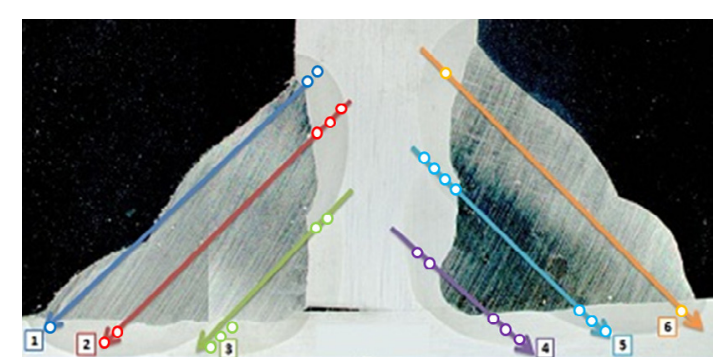

(a)

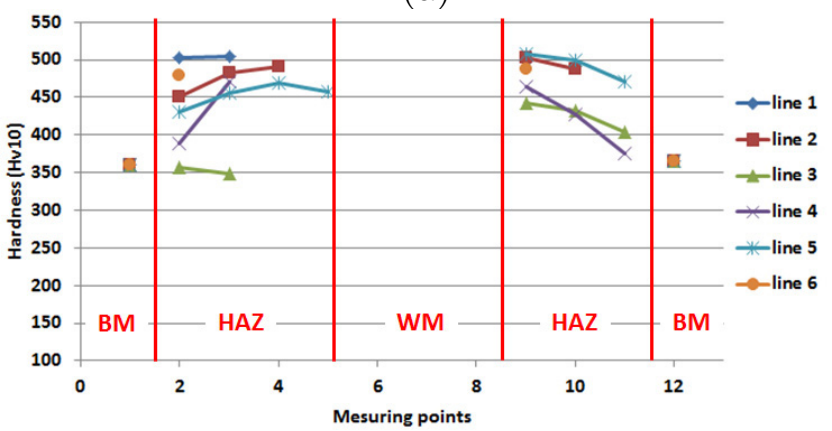

(b)

Fig. 1. (a) Hardness specimen; (b) Hardness measurement in the BM and HAZ materials.

verify the added value of taking mechanical properties of thermally affected materials into account, a FE numerical analysis on a welded substructure submitted to impact loading is undertaken.

\section{Experimental program}

The manufacturing process and tensile specimen geometries, as well as experimental tests, measurement facilities and analysis procedures are presented in this section.

\subsection{Materials}

The BM is a hot-rolled HSS that offers high strength, ductility and good weldability. Due to the small size of the HAZ, dumbbell tensile specimens cannot be extracted directly from the welded joint to perform quasi-static and dynamic tests. As a consequence, a specific approach has been developed to generate the HAZ material using a thermal treatment. Both hardness and grain size are controlled to validate the replicated HAZ with respect to one from a welded joint. Grain size is measured by the grain size number through the following relation (defined by the norm [10]):

$$
M=8.2^{G}
$$

where $M$ is the number of grains per $\mathrm{mm}^{2}$ and $G$ the grain size number on the observed sample surface. The Vickers hardness is measured along 6 paths across the BM, HAZ and WM. As seen in Figure 1, the hardness between BM and HAZ increases significantly.
The hardness in the heat affected material is not constant along the path. The question is: how to take the gradient of properties into account? Our choice is to determine the extreme characteristics of the HAZ: on the one hand these are given by the BM and, on the other hand, by the maximum hardness zone in the HAZ. This hardness is then considered for the heat treatment. Furthermore, this maximum hardness is located where the maximum deformation will occur under dynamic loads due to high geometrical stress concentration. The aim of this heat treatment is not to re-create the real and complex thermal cycle induced by the welding process (i.e. by using a Gleeble ${ }^{\circledR}$ thermomechanical simulator), but only to obtain specimens with mechanical properties close to those of a HAZ obtained by welding.

The heat treatment is detailed below. The sample is put in a preheat furnace. The temperature is increased to a specific temperature (austenitic temperature $-T c$ ) and remains constant for several minutes. The sample is then tempered to fix the microstructure. To adjust the final hardness of the sample a low temperature stress-relieving treatment is performed. A preliminary study was carried out to adjust the temperature $(T c)$ to obtain the correct austenite grain size in the material before the tempering (Fig. 2a). The first temperature tested was too low to completely remove ferrite and pearlite in the material. As the austenitic temperature rises, the hardness and the grain size number decrease. The HAZ microstructure and the hardness are finally validated by comparison with the HAZ obtained in the welded joint (Fig. 2).

To avoid excessive distortions of the specimen, the thermal cycle is applied on the rough sample, and then the final geometry is machined. To prevent any excessive heating of specimens, a careful machining with a high flow of lubricant is used. The heat treatment process is applied to 5 samples per batch: 4 samples will be machined at the tensile specimen geometry; the last one is the batch control specimen. This one is cut in the middle to make hardness measurements on the position corresponding to the gage cross section (Fig. 3). 6 batches of 5 samples are made. For each batch, hardness measurements remain constant for all samples: less than $2 \%$ of dispersion is measured.

\subsection{Specimen geometries}

Quasi-static and dynamic tests have been performed on smooth axisymmetric specimens at room temperature. As shown in Figure 4, specimens with different gage lengths and diameters are required to cover a large range of strain rates from quasi-static to $1350 \mathrm{~s}^{-1}$. The quasistatic geometry complies with the standards (Fig. 4a). Different dynamic geometries are considered in order to compare BM and HAZ properties at the same strain rate. Gage diameters have been adapted to perform dynamic tests at the same pre-loading force on a pre-stretched tension bar. The strain rates are measured in the gage length of the sample during plasticity before necking and 


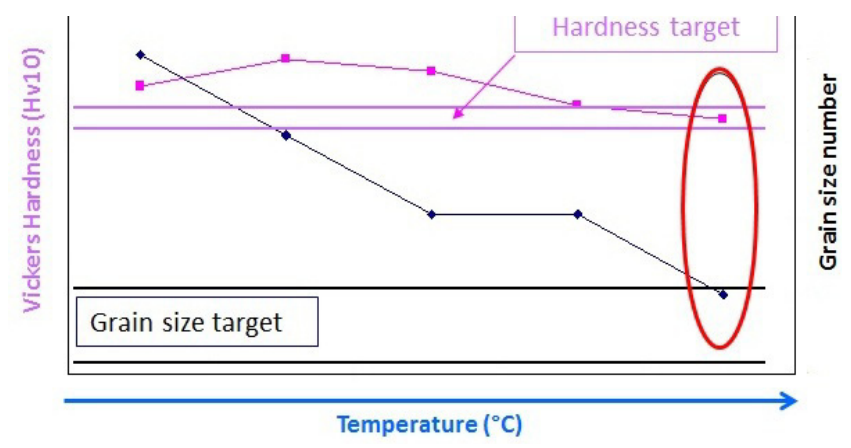

(a)

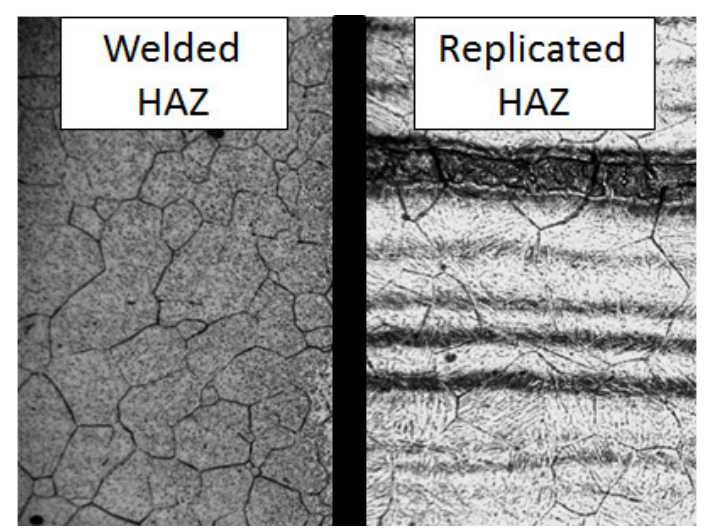

(b)

Fig. 2. (a) Description of the optimized heat treatment; (b) Comparison of welded and replicated HAZ microstructure.

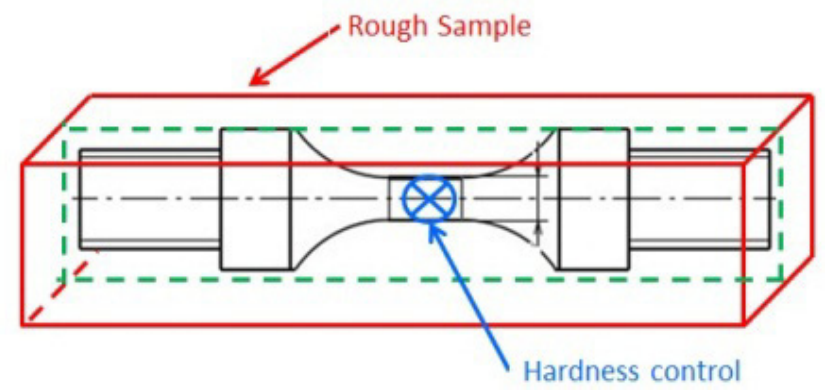

Fig. 3. Rough sample.

after the wave stabilization. All the tests were performed 3 times for quasi-static tests and 5 times for dynamic tests.

\subsection{Pre-stretched tension bar}

This experimental program, based on dynamic loading was carried out using the Hopkinson bar technique. As the high ductility properties of the base material and heat affected zones are observed under quasi static conditions, a high duration time is required. For that, as shown by Figure 5, a pre-stretched bar device, based on the original concept proposed by Albertini [11], is used to determine the set of flow curves for moderate strain rates up to failure. Both bars have a common diameter of $11 \mathrm{~mm}$ and the specimen is inserted between positions $\mathrm{D}$ and $\mathrm{E}$. The pre-loading force $\mathrm{F}$ - stabilized between A and B - is provided by two quasi-static loads applied on the input bar (Fig. 5).

This ensures the storage of elastic energy which is abruptly released when the brittle fracture of the fuse occurs at position B. The elastic wave propagates with a constant duration time depending on the length of the pre-stretched part $(\mathrm{AB})$ along the input bar and loads the specimen up to failure. A set of three full strain bridges (HBM LY $4135 \Omega-1.5 \mathrm{~mm}$ in length) is strategically positioned along the experimental set-up to detect the elastic wave system using a high speed recorder (Yokogawa DL $750-4$ channels). The data are finally recorded to compute the stress/strain curves [12]. Here, position B is chosen so that the reflected wave cannot be superimposed with the incident wave at the position of the strain gage bonded at $\mathrm{C}$. The strain rate value is modified by varying the pre-loading force $\mathrm{F}$ of the pre-stretched device.

\subsection{Specimen contour evolution by video tracking}

Based on previously published works [13, 14], a methodology has been set up to measure the specimen contour evolution after necking to obtain the true stressstrain curve of the material. A CMOS high speed camera (Photron APX RS 3000) is added to record the contour evolution of the specimen during the test. As sharp edges between the background and the specimen are needed, a flashlight is placed behind the specimen so as to highlight its shadow.

Then, the elongation and reduction of the specimen can be quantified using a Matlab ${ }^{\circledR}$ routine. Figure 6 provides details on the optical measurement device and the image analysis process. The speed of the camera is set to 75000 and $90000 \mathrm{f} / \mathrm{s}$ depending on the range of strain rates so as to ensure over 20 images during the test.

Measurement of the reduction in diameter, in particular the smallest diameter after necking, is obtained by a tracking algorithm with a filter on the contrast gradient. The minimum diameter is the minimum distance between the two filtered edges of the specimen. The first image, just before the test starts, is used to calibrate the original gage diameter of the specimen (in pixels) (Figs. 6b$6 \mathrm{~d}$ ). The final diameter measured by video tracking (last diameter at fracture initiation) is compared to the postmortem diameter to validate the digital calibration. The true stress-strain curve is obtained using the following relations [15]:

$$
\varepsilon_{\text {true }}=2 \ln \left(D_{0}\right)-2 \ln (D)
$$

where $D_{0}$ is the initial gage diameter and $D$ is the minimum diameter in the necked area.

$$
\sigma_{\text {true }}=\sigma_{z z}=\frac{4 F}{\pi \cdot D^{2}}
$$

where $F$ is the force measured during the test. 


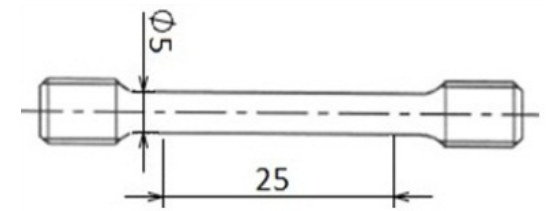

(a)

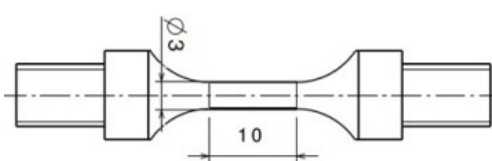

(b)

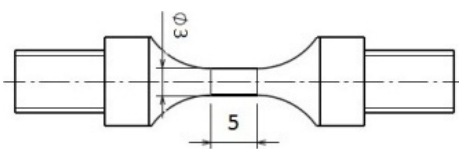

(d)

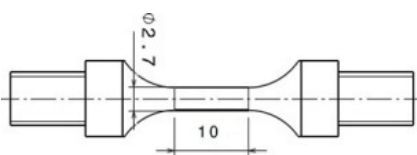

(c)

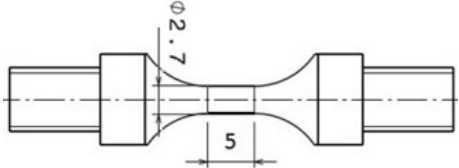

(e)

Fig. 4. Geometries of specimens for tensile tests: (a) quasi-static for BM and HAZ; (b-c) dynamic for BM; (d-e) dynamic for HAZ.

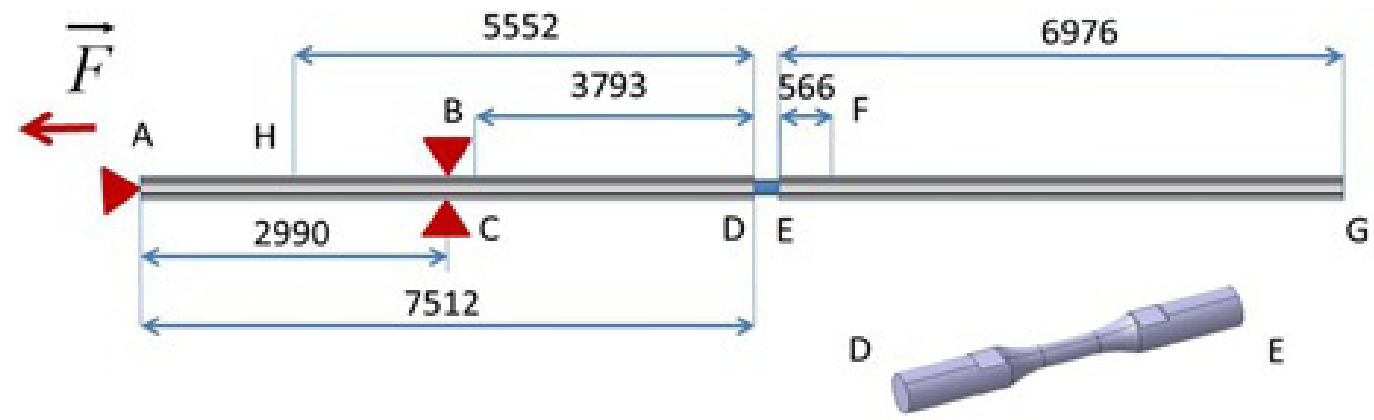

Fig. 5. Sketch of the pre-stretched tension bar - Dimensions in mm.

The high speed camera is limited to an image resolution of $64 \times 250$ pixels on the specimen gage section. This low resolution and the limited number of recorded images (about 20) lead to an error of approximately $0.05 \mathrm{~mm}$ on the measured diameter. Therefore, after the onset of necking, an error of about $50 \mathrm{MPa}$ on the true stress and 0.03 on the true strain is estimated.

\subsection{Bridgman-LeRoy correction}

The true stress-true strain diagram cannot be computed beyond necking, unless the effects of necking on the geometry of the tensile specimen and the stress state are accurately quantified. Necking produces a triaxial stress state that does not reflect the true uniaxial flow stress of the material. Therefore, the true uniaxial stress $\left(\sigma_{z z}\right)$ must be multiplied by a correction factor to correct the effect of the triaxial stresses and obtain the equivalent stress $\left(\sigma_{e q}\right)$. Necking effects are easily quantified for specimens with circular cross-sections using the Bridgman correction approach. In the center of the sample the triaxiality stress ratio is calculated by the relation [16]:

$$
\sigma *=\frac{1}{3}+\ln \left(1+\frac{a}{2 R}\right)
$$

where $a$ is the current radius of the neck and $R$ is the radius of curvature of the neck surface in the longitudinal plane at the minimum section. The Bridgman and LeRoy correction $[16,17]$ is defined by:

$$
\sigma_{e q}=\frac{\sigma_{z z}}{\left(1+\frac{2 R}{a}\right) \ln \left(1+\frac{a}{2 R}\right)}
$$

LeRoy [17] found that the neck geometry could be calculated with the following approximation and gives good results for steel with $\kappa=1.1$ :

$$
\frac{a}{R}=\kappa\left(\overline{\varepsilon_{p}}-\varepsilon_{u}\right) \text { for } \overline{\varepsilon_{p}}>\varepsilon_{u}
$$

\section{Experimental results}

In the first part of this section, the BM and HAZ mechanical behaviors are compared using their true stressstrain behavior laws. The strain-rate dependency of each material is investigated in the second part. Those true stress-strain behavior laws are obtained up to failure by using the specimen contour evolution by video tracking associated with the Bridgman-LeRoy correction. 


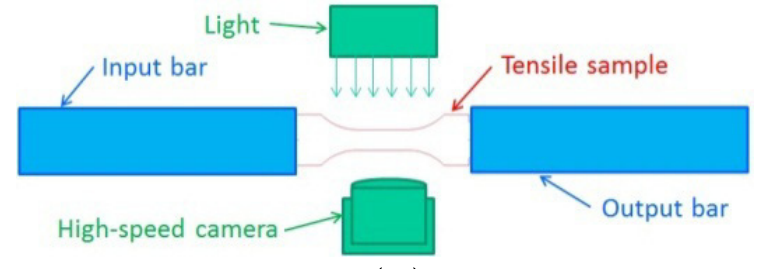

(a)

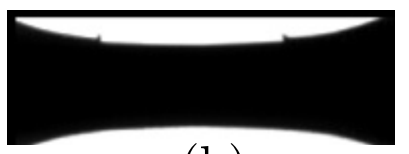

(b)

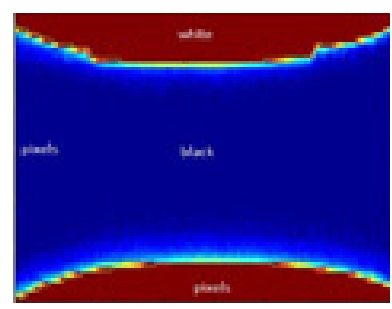

(d)

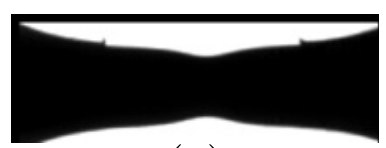

(c)

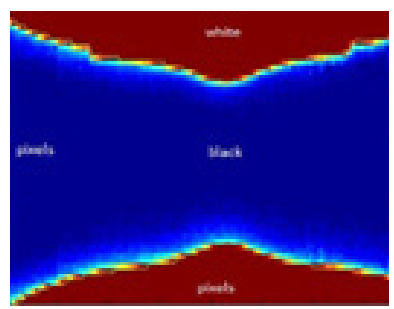

(e)
Fig. 6. (a) Optical measurement device; (b-c) Initial images at the start of test and during test; (d-e) Images after filtering procedure.

\subsection{Quasi-static BM and HAZ tests results}

The quasi-static true stress-strain behaviors for both materials are presented in Figure 7. The specimen geometries are referred as BM-1, HAZ-QS and HAZ-1 (Fig. 4). Except for the experimental scatter at failure, the true stress-strain behavior related to the HAZ with the two different specimen geometries are similar (curves HAZ1 and HAZ-QS in Fig. 7). The Bridgman-LeRoy correction allows us to determine the local material behavior. The microstructure of the MB is a martensitic lath structure which provides ductility and toughness. The heat treatment has created a new martensitic structure with a smaller grain size number. So, the yield stress and ultimate tensile stress have increased on the HAZ material but strain at failure has decreased. In fact, the applied thermal cycle is known to act as a heat treatment which hardens the material [18].

An alternative way, based on an engineering approximation, allows us to calibrate the HAZ behavior law by scaling with a constant factor, the BM behavior law (yield stress) related to the hardness of HAZ material. The obtained HAZ behavior is quite close to the real measured HAZ behavior (Fig. 7).

\subsection{BM strain rate dependency}

In this section, the BM true stress-strain behavior is analyzed for strain rates from the quasi-static range up to
$1300 \mathrm{~s}^{-1}$ (Fig. 8). The specimen geometries are referenced as BM-1 and BM-2 which only differ by the gage length (Fig. 4). Only the experimental scatter at $300 \mathrm{~s}^{-1}$ with the BM-1 specimen geometry is presented here. To compare the influence of the specimen geometry, additional tests at $300 \mathrm{~s}^{-1}$ (and $350 \mathrm{~s}^{-1}$ ) for both BM specimen geometries (BM-1 and BM-2) are performed. During tests at $350 \mathrm{~s}^{-1}$ on the BM-2 specimen geometry, a problem with the video occurred, only the pre-necking behavior law and the stress-strain point at failure, calculated post-mortem, are presented. We observe that the BM-2 hardening law is contained in the BM-1 experimental scatter at $300 \mathrm{~s}^{-1}$. All mean curves, from quasi-static up to $1300 \mathrm{~s}^{-1}$, are contained in the BM-1 experimental scatter at $300 \mathrm{~s}^{-1}$, so the BM hardening is not strain rate sensitive.

Thanks to the specimen contour tracking and the Bridgman-LeRoy correction, we can conclude that the geometry effects after necking do not seem to impact the BM material behavior or it is drowned in the experimental scatter. Regarding the strain at failure, a reverse engineering approach, based on the engineering stress and strain behavior laws up to failure, is however needed to identify a geometry insensitive failure criterion. Triaxiality factor for quasi-static and dynamic tests (with the different geometries) are in the order of 0.8 at failure in the center of the specimen.

\subsection{HAZ strain rate dependency}

In this last part, the HAZ behavior is studied at different strain rates from quasi-static up to $1350 \mathrm{~s}^{-1}$. The specimen geometries are referenced by HAZ-1 and HAZ2 (Fig. 4). To study and validate the repeatability of the applied thermal cycle, two sets of 4 samples are tested with the same strain rate $\left(150 \mathrm{~s}^{-1}\right)$. One set shows more scatter (a relative difference of $7 \%$ on the strain at failure) against $1 \%$ for the other. Nevertheless, the both two mean curves are included in the experimental scatter of the other one (Fig. 9). It can be concluded that thermal cycle is a repeatable operation.

Firstly, Figure 10 shows a softening between quasistatic and dynamic tests results, both on yield stress and stress at failure. Secondly, for dynamic tests, the strain rate dependency between $150 \mathrm{~s}^{-1}$ and $1350 \mathrm{~s}^{-1}$ is not explicit. Indeed, with the HAZ-1 geometry, there is a softening with the increase of the strain rate $\left(150 \mathrm{~s}^{-1}\right.$ and $580 \mathrm{~s}^{-1}$ ). Tests performed with the HAZ-2 geometry at $1350 \mathrm{~s}^{-1}$ shows a slight hardening by comparison to HAZ1 dynamic tests results. Experimental scatters could not explain this gap. Stress triaxiality factor are quite similar between all those tests.

At this time we are not able to explain those unexpected results. Regarding the softening, the microstructure and the chemical composition generated by the heat treatment will be deeply analyzed across the tested specimens. Nevertheless, hardness measurements, across a longitudinal section in the post-mortem sample, show a relatively constant value. Regarding a potential geometry effect, the quasi-static tests performed on the HAZ-2 
J. Carrier et al.: Mechanics \& Industry 18, 301 (2017)

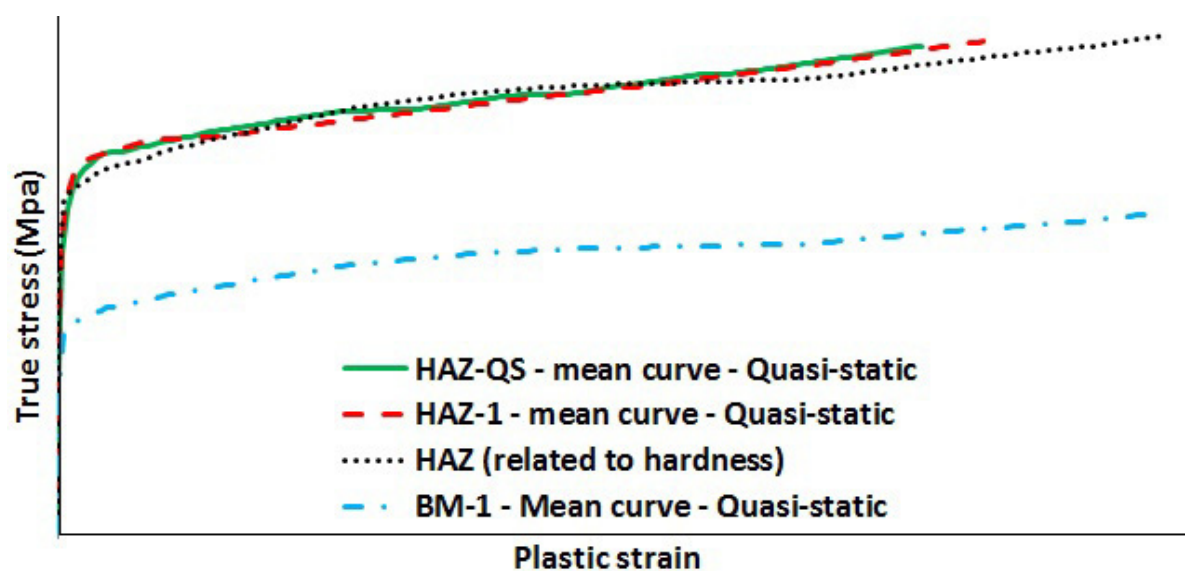

Fig. 7. BM and HAZ quasi-static true stress-strain curves.

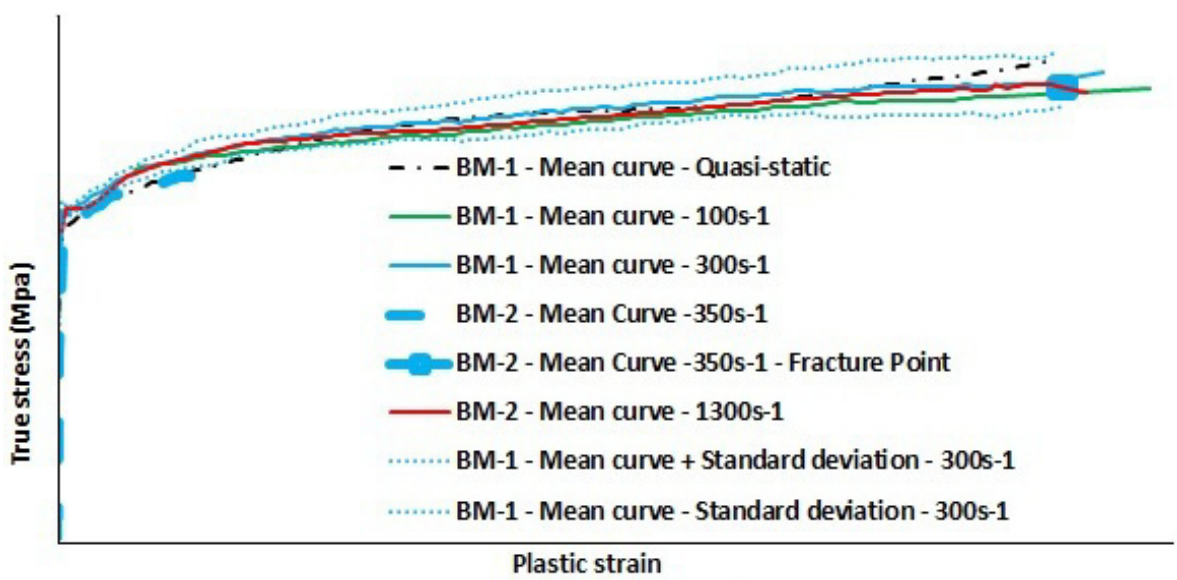

Fig. 8. BM - True stress-strain curve - Strain rate dependency.

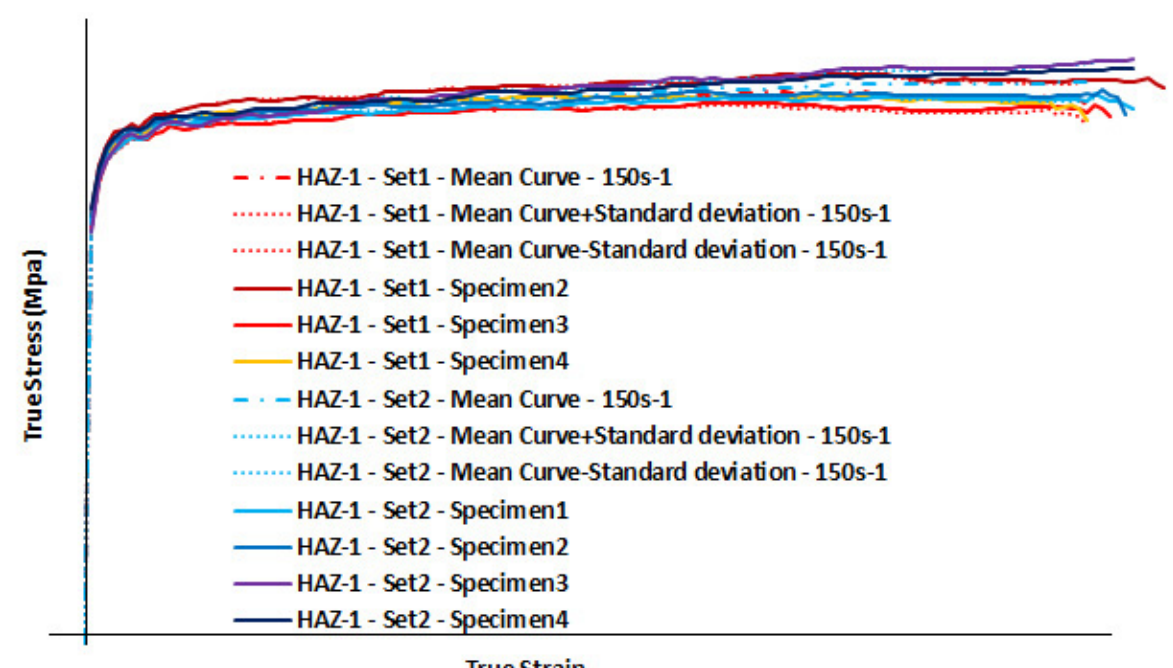

True Strain

Fig. 9. HAZ - True stress-strain curve - Experimental scatter. 


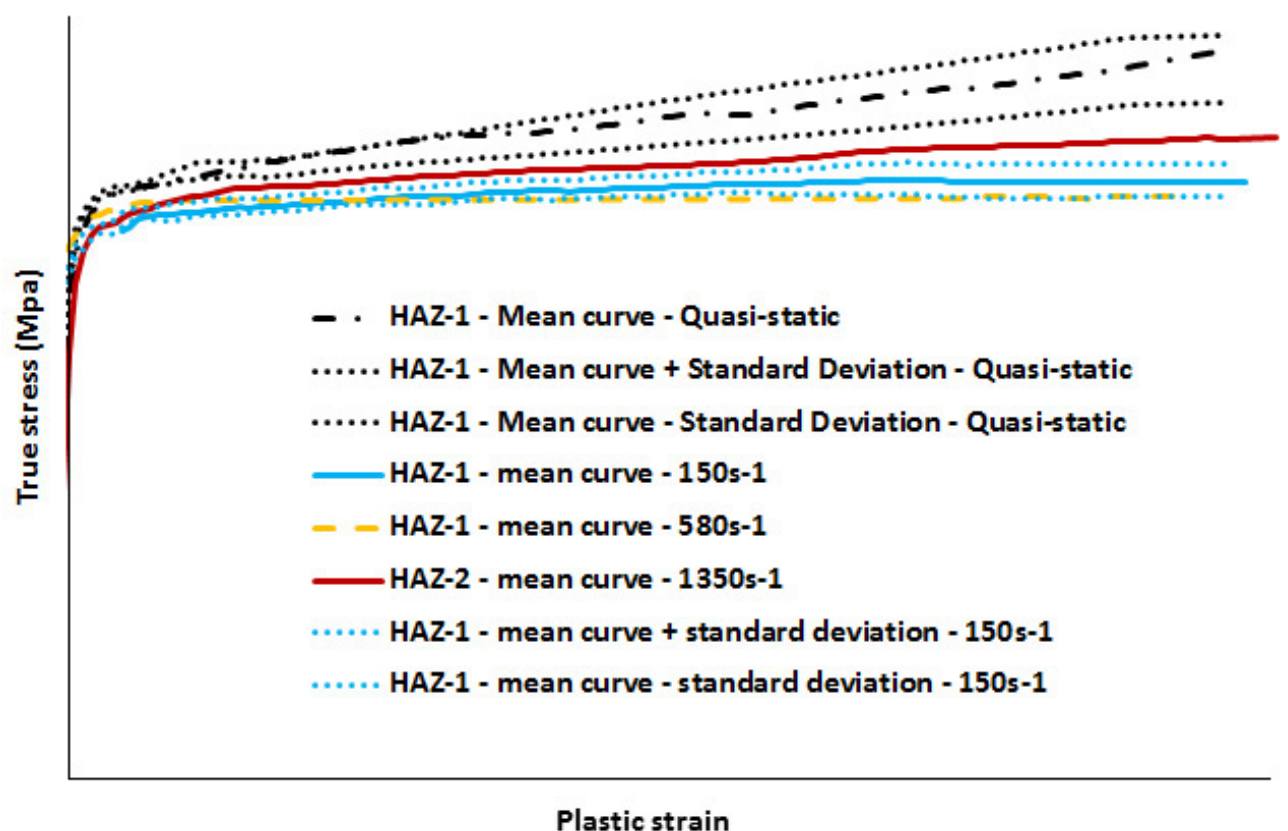

Fig. 10. HAZ - True stress-strain curve - Strain rate dependency.

and HAZ-1 specimen geometries led to quite similar true stress-strain curves. A comparison on dynamic tests at $580 \mathrm{~s}^{-1}$ will be lead. A dynamic test with a thermocouple at an intermediate strain rate $\left(1 \mathrm{~s}^{-1}\right)$ may provide an issue.

\section{Modeling of a welded joint dynamic test}

As a first attempt to verify the added value of taking mechanical properties of thermally affected materials into account, a 2D plane strain FE numerical analysis (LsDyna) on a T-shape welded substructure submitted to a lateral impact loading is undertaken. A cross-sectional view provides the detailed geometry of the welded joint (Fig. 11). The parameters of a Johnson-Cook behavior law were identified on the basis of previous experimental results for the MB and HAZ materials, also for the Weld Metal (not presented here). In order to highlight the effect of the HAZ behavior on the welded joint behavior, we performed two simulations:

- One considering the HAZ material equal to the BM (model 1);

- One with the HAZ behavior, we determined in this paper (model 2).

Global Force-Displacement results are quite similar as the modification introduced by the welding process is quite local. On the contrary, local equivalent plastic strains fields show differences:

- Model 1 (Fig. 12a) leads to a strong plastic strain localization in the WM;

- Model 2 (Fig. 12b) shows a higher plastic strain at the $\mathrm{BM} / \mathrm{HAZ}$ interface.
Moreover, the HAZ material undergoes low plastic strains during the impact test. It appears that the high yield stress plays the key role in the HAZ behavior. Strain rate measures in the weld metal bead (WM) range from $1300 \mathrm{~s}^{-1}$ to $1500 \mathrm{~s}^{-1}$ at the HAZ/BM interface. These strain rates correspond to the strain rates chosen for the material behavior laws identification.

This plastic strain localization will lead to different fracture modes that are then compared with experimental results. This comparison will be presented in a further paper.

\section{Conclusion and prospects}

This paper presents the evolution of the behavior between BM and HAZ materials of a HSS fillet welded joint assembly from quasi-static to dynamic loadings. Firstly, a specific approach is developed to generate the HAZ material using a thermal treatment. Hardness and grain size are used to validate the replicated HAZ material. This approach appears efficient and repeatable. To cover a large range of strain rates, different specimen geometries are needed. A direct method, using video tracking of the specimen geometry and Bridgman-LeRoy correction is used to identify the true stress-strain curve. Secondly, quasi-static and dynamic behaviors from BM and HAZ are compared. The thermal cycle affects significantly the material behavior. Indeed, on the HAZ the hardening is increased whereas strain at failure is decreased. Regarding the strain rate effects, it appears that the BM is insensitive while the HAZ presents a softening between quasistatic and dynamic tests. Further analyses are needed on HAZ sample (chemical composition and microstructure) to understand this dynamic material softening. A first 


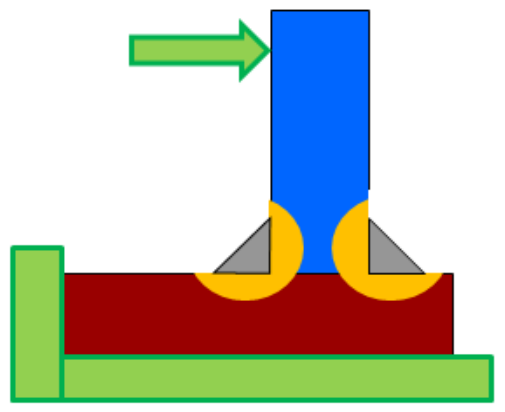

(a)

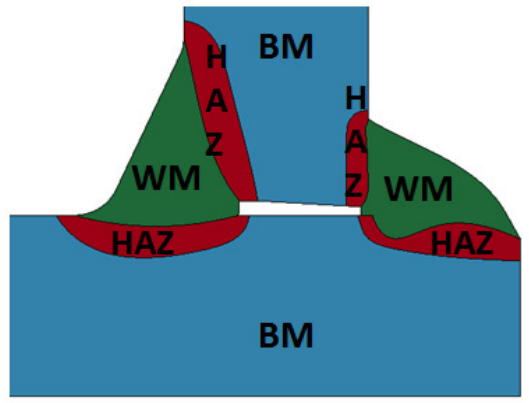

(b)

Fig. 11. (a) Experimental schematic drawing; (b) T-shape welded joint modeling.

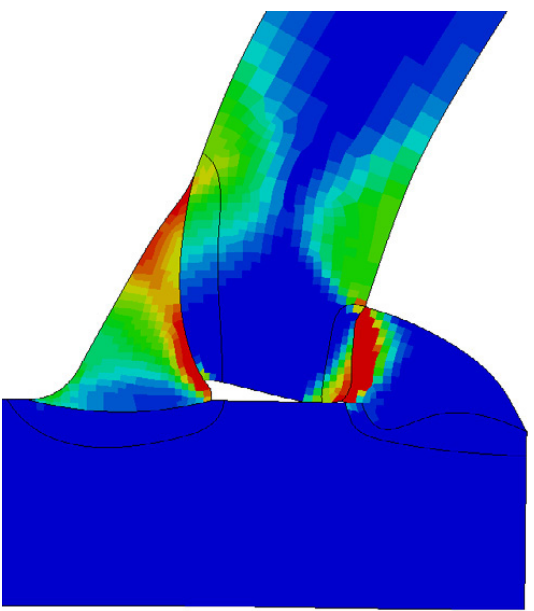

(a)

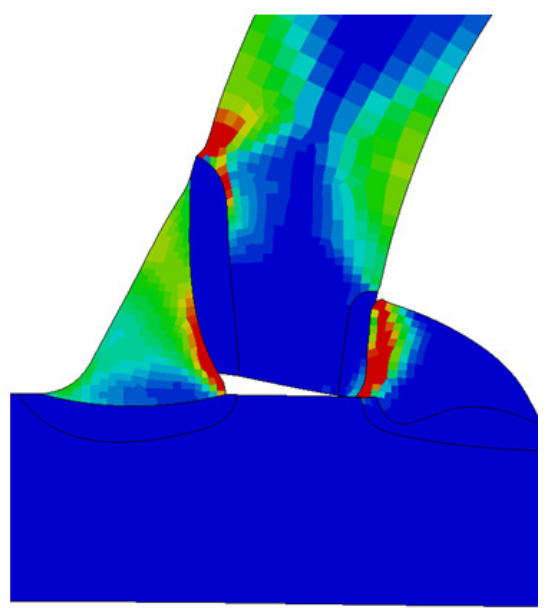

(b)

Fig. 12. Welded joint dynamic test - equivalent plastic strain: (a) Model 1; (b) Model 2.

FE numerical analysis of dynamic impact test on a Tshape welded joint shows the strong influence of the HAZ material properties on the plastic strain localization and consequently on the fracture mode of the assembly.

\section{References}

[1] E. Markiewicz, P. Ducrocq, P. Drazetic, G. Haugou, T. Fourmentraux, J.Y. Berard, Material behavior law identification for the various zones of the spot-weld under quasi-static loadings, Int. J. Mater. Product Technol. 16 (2001) 484-509

[2] B. Langrand, E. Markiewicz, Strain-rate dependence in spot welds: Non-linear behavior and failure in pure and combined modes I/II, Int. J. Impact Eng. 37 (2010) 792805

[3] T. Wang, Modelling of welded thin-walled aluminium structures, Ph.D. thesis, NTNU, 2006

[4] F. Labesse-Jied, B. Lebrun, E. Petitpas, J.L. Robert, Multiaxial fatigue assessment of welded structures by local approach, Proceedings of the 6th Int. Conference on Biaxial/Multiaxial Fatigue and Fracture., Lisbon, 2001, Editor: M. De Freitas, 81-89
[5] T.K. Chan, R.F.D Porter Goff, Welded aluminium alloy connections: test results and BS8118, Thin-Walled Structures 36 (2000) 265-287

[6] H.G. Hildrum, Stiffened aluminium plates subjected to impact loading, Ph.D. thesis, NTNU, 2002

[7] P. Gaudreault, A. Bouamoul, R. Durocher, B. St-Jean, Finite element modeling of light armoured vehicle welds heat affected zone subjected to anti-vehicular blast landmine loading, a summary of the numerical model and field experiment, Proceedings of the 22nd Int. Symposium on Ballistics, Vancouver, BC, Canada, 2005

[8] B. Gailly, Étude du comportement dynamique et de la rupture de trois aciers à blindage, Ph.D. thesis, Mines de Paris, 1996

[9] P. Chevrier, Mécanique et mésomécanique de l'écaillage essais expérimentaux et critères de rupture. Étude d'un alliage d'aluminium et d'un acier à blindage, Ph.D. thesis, Université de Metz, 1998

[10] NF EN ISO 643, Aciers - Détermination micrographique de la grosseur de grain apparent, Avril 2013

[11] C. Albertini, M. Montagnani, Testing techniques based on the split Hopkinson bar, Mechanical Properties at High Strain Rates 21 (1974) 22-32 
[12] H. Kolsky, Stress waves in solids, Dover Publications Inc., New York, 1963

[13] O.S. Hopperstad, T. Borvik, M. Langseth, K. Labibes, C. Albertini, On the influence of stress triaxiality and strain rate on the behavior of a structural steel. Part I. Experiments, Eur. J. Mech. A/Solids 22 (2003) 1-13

[14] T. Borvik, O.S. Hopperstad, T. Berstad, On the influence of stress triaxiality and strain rate on the behavior of a structural steel. Part II. Numerical study, Eur. J. Mech. A/Solids 22 (2003) 15-32
[15] M. Alves, N. Jones, Influence of hydrostatic stress on failure of axisymmetric notched specimens, J. Mech. Phys. Solids 47 (1999) 643-667

[16] P.W. Bridgman, Studies in Large Plastic Flow and Fracture, McGraw-Hill, 1952

[17] G. Le Roy, J.D. Embury, G. Edward, M. F. Ashby, A model of ductile fracture based on the nucleation and growth of voids, Acta Metall. 29 (1981) 1509-1522

[18] G. Murry, Traitements thermiques dans la masse des aciers. Partie 1, Techniques de l'ingénieur, 2000 